\title{
Fitossociologia de plantas daninhas em cultivo de feijão-caupi no semiárido mineiro
}

\author{
Marlon Lopes LACERDA ${ }^{1}$, Dhanne Lucas Soares SILVA'1, Ignacio ASPIAZÚ1, \\ Abner José de CARVALHO ${ }^{1}$, Simônica Maria de OLIVEIRA ${ }^{1}$, Rafael Fernandes SILVA ${ }^{1 *}$ \\ ${ }^{1}$ Universidade Estadual de Montes Claros, Montes Claros, MG, Brasil. \\ *E-mail: rafael.fernandes21@yahoo.com.br \\ (ORCID: 0000-0002-8708; 0000-0001-5888-1005; 0000-0002-0042-3324; \\ 0000-0002-6644-5307; 0000-0002-3087-7386; 0000-0002-0477-9934)
}

Recebido em 30/09/2020; Aceito em 29/11/2021; Publicado em 21/12/2021.

\begin{abstract}
RESUMO: O presente trabalho teve como objetivo caracterizar a dinâmica da comunidade infestante de plantas daninhas em cultivo do feijão-caupi no semiárido mineiro. Os tratamentos consistiram na coleta das plantas daninhas aos 7, 14, 21, 28, 35, 42, 49, 56, 63 dias após a emergência (DAE), posteriormente foi feito o controle da comunidade infestante por capina mecânica. A coleta de plantas daninhas foi feita pelo método padrão do quadrado inventário, lançado aleatoriamente na área útil de cada parcela, recolhendo todas as plantas. Foram determinados o número de indivíduos por espécie em cada parcela e o número total por coleta. Após a identificação e contagem das espécies, foi realizado o cálculo das variáveis fitossociológicas: Frequência, Densidade, Abundância, Frequência relativa, Densidade relativa, Abundância relativa, Dominância relativa, Índice de valor de importância (IVI), Índice de valor de cobertura (IVC) e Índice de similaridade (IS). As espécies Portulaca oleracea, Amaranthus viridis e Sorghum bicolor apresentaram maiores valores de IVI. Foi possível afirmar que é alta a similaridade florística das espécies de plantas daninhas que ocorreram durante o ciclo do feijão-caupi. Quanto ao Índice de valor de Cobertura (IVC), destacaram-se as espécies Portulaca oleracea, Sorghum bicolor e Senna obustifolia.
\end{abstract}

Palavras-chave: comunidade infestante; Vigna ungiculata; levantamento fitossociológico.

\section{Phytosociology of weeds in cultivation of cowpea in the semi-arid region of Minas Gerais}

\begin{abstract}
The present work aimed to characterize the dynamics of the weed community in cultivation of cowpea in the semi-arid region of Minas Gerais. The treatments consisted of collecting the weeds 7, 14, 21, 28, 35, 42, 49, 56, 63 days after emergence (DAE); following each collection, the weed community was controlled by mechanical weeding. The collections were carried out using the standard method of the inventory square, randomly launched in the useful area of each plot, collecting all the plants. The number of individuals per species in each plot and the total number per collect were determined. After identifying and counting the species, the phytosociological variables were calculated: Frequency, Density, Abundance, Relative frequency, Relative density, Relative abundance, Relative dominance, Importance value index (IVI), Coverage value index (CVI) and Similarity Index (SI). The species Portulaca oleracea, Amaranthus viridis and Sorghum bicolor presented the largest IVI. It was possible to affirm that the floristic similarity of the weed species that occurred during the cowpea cycle is high. The species Portulaca oleracea, Sorghum bicolor and Senna obustifolia presented the highest CVI values.

Keywords: infestant comunnity; Vigna ungiculata; phytosociological survey.
\end{abstract}

\section{INTRODUÇÃO}

O feijão-caupi (Vigna unguiculata) é uma espécie cultivada que possui destaque dentro do gênero Vigna, pois compreende quase a totalidade das cultivares melhoradas. A cultura constitui uma das principais fontes de proteína vegetal e atua, também, como importante fonte de emprego principalmente para as regiões Norte e Nordeste do Brasil (FREIRE FILHO et al., 2011), além de conter todos os aminoácidos essenciais, carboidratos, vitaminas e minerais, possuir grande quantidade de fibras alimentares e baixa quantidade de gordura, sendo que a composição destes nutrientes pode variar conforme as práticas agronômicas realizadas na cultura e manejo pós-colheita (ANDRADE, 2010).
Em crescente cultivo também no centro-oeste por grandes produtores, a média da produção nacional do feijãocaupi no ano de 2018 foi de 789,8 mil toneladas, com produtividade de $521 \mathrm{~kg} \mathrm{ha}^{-1}$ (CONAB, 2019). E dentre os fatores limitantes para a produção do feijão-caupi, a interferência causada por plantas daninhas é um dos problemas que mais afeta a produção, pois estas agem competindo por água, luz e nutrientes, além de liberarem substâncias alelopáticas, afetando a qualidade e a quantidade da produção. Esses fatores diretos ou indiretos influenciam negativamente na produtividade e desenvolvimento da cultura e são caracterizadas como interferências (VASCONCELOS et al., 2012). Em estudos realizados por 
Oliveira et al. (2010), verificaram que a ausência de controle de plantas daninhas pode provocar reduções na produtividade de até $90 \%$ em função da competição da cultura e as espécies infestantes. Oliveira et al. (2010), trabalhando com feijão-caupi, cultivares EV x 91-2E-2, BR8 Caldeirão e BR IPEAN V69, detectaram uma redução de $59,78,68,18$ e $90,18 \%$ na produtividade respectivamente.

Um problema relevante em áreas de cultivo é o controle de plantas daninhas, devido à capacidade de se destacarem e competirem pelos recursos naturais. Portanto, para adotar uma medida de controle no manejo de plantas daninhas é imprescindível o conhecimento das plantas presentes na cultura, sendo necessário um diagnóstico prévio e quantificação dessas populações de plantas. Batista et al. (2017) determinaram a fitossociologia de plantas daninhas em alguns das principais cultivares de feijão-caupi do Brasil, de porte ereto e prostrado cultivados no semiárido mineiro. Nos cultivares de porte ereto, as famílias Amaranthaceae, Euphorbiaceae, Asteraceae e Convolvulaceae foram as mais importantes. Já nos cultivares de porte prostrado, foram as famílias Amaranthaceae, Asteraceae e Malvaceae. a Portulaca oleracea e a Amaranthus spp. foram as espécies mais importantes, e o índice de similaridade entre os cultivares de porte ereto e prostrado foi de $72 \%$, e nove das 16 famílias ocorreram em cultivares dos dois portes. Lima et al. (2016) quantificaram as principais espécies de plantas daninhas presentes, em diferentes períodos, na cultura do feijão-caupi, no município de Vitória da Conquista - BA, e encontraram 42 espécies de plantas daninhas, distribuídas em 12 famílias. A maioria das espécies encontradas foi da família Poaceae, Amaranthaceae e Asteraceae. As espécies que predominaram na área foram Brachiaria plantaginea, Amaranthus bybridus var. paniculatus, Amaranthus spinosus, Blainvillea biaristata, Portulaca oleracea e Malvastrum coromandelianum.

Através da utilização da fitossociologia é possível identificar quais são essas populações, assim como a frequência, abundância e densidade das plantas daninhas presentes em determinado cultivo (MARQUES et al., 2010). Dessa forma, o objetivo deste trabalho foi caracterizar a dinâmica da comunidade infestante de plantas daninhas ao longo do ciclo da cultura do feijão-caupi no semiárido mineiro.

\section{MATERIAL E MÉTODOS}

O experimento foi realizado na Fazenda experimental da Universidade Estadual de Montes Claros, localizada no município de Janaúba, MG, nas coordenadas geográficas de $15^{\circ} 47^{\prime} 50^{\prime \prime} \mathrm{S}, 43^{\circ} 18^{\prime} 31^{\prime \prime} \mathrm{W}$ e altitude de $516 \mathrm{~m}$. O clima da região é do tipo "Aw" (tropical chuvoso, savana com inverno seco) segundo classificação de Köppen. O solo foi classificado como Latossolo Vermelho eutrófico.

Os tratamentos consistiram na coleta das plantas daninhas aos 7, 14, 21, 28, 35, 42, 49, 56, 63 dias após a emergência (DAE), e logo após foi feito o controle da comunidade infestante através de capina mecânica. O delineamento experimental foi o de blocos ao acaso, com nove tratamentos e quatro repetições. As parcelas foram compostas por seis fileiras de feijão-caupi, espaçadas de 0,5 $\mathrm{m}$ entre si, com $4 \mathrm{~m}$ de comprimento, com área útil sendo as quatro fileiras centrais de cada parcela. A área foi preparada de forma convencional, com uma aração e duas gradagens. Antes da semeadura, foi retirada uma amostra composta de solo, na camada de $0-20 \mathrm{~cm}$, para determinação dos atributos químicos. A adubação foi feita conforme as recomendações adotadas para a cultura (Melo et. al., 2005) e constou de 250 $\mathrm{kg} \mathrm{ha}{ }^{-1}$ da formulação NPK 4-30-10 no plantio e mais $20 \mathrm{~kg}$ $\mathrm{ha}^{-1}$ de $\mathrm{N}$ em cobertura no estádio $\mathrm{V} 4$, usando como fonte nitrogenada a ureia. Após o preparo do solo, utilizou-se de uma semeadora-adubadora para a realização do plantio e distribuição do adubo nas fileiras. O plantio foi realizado no mês de maio de 2017, época que, como há condições de irrigar, apresenta condições climáticas para o desenvolvimento da cultura no norte de Minas Gerais, colocando-se cerca de 15 sementes por metro.

A cultivar utilizada foi a BRS Itaim, que possui hábito de crescimento determinado, porte ereto e alta resistência ao acamamento, e cuja média de produtividade de grãos é de $2.600 \mathrm{~kg} \mathrm{ha}^{-1}$, sendo recomendada especialmente para cultivo em regime de sequeiro, em função da maior tolerância ao déficit hídrico. Tanto no regime de sequeiro quanto no irrigado recomenda-se o uso de 200 mil plantas por hectare (EMBRAPA, 2016). A aplicação de inseticidas foi realizada de acordo com a demanda da cultura. $O$ experimento foi conduzido de maio a setembro de 2017 , com irrigação do tipo aspersão convencional durante todo o ciclo da cultura, tendo sido aplicada uma lâmina total de $350 \mathrm{~mm}$ em um turno de rega de três dias.

Para a coleta das plantas daninhas, foi utilizado o método padrão do quadrado inventário, um quadrado de $0,5 \mathrm{~m}$ x 0,5 $\mathrm{m}$, que foi lançado aleatoriamente uma vez na área útil de cada parcela conforme descrito por Braun-Blanquet (1979). As plantas daninhas foram cortadas rente ao solo, colocadas em sacos de papel para posterior identificação. Em seguida, as espécies coletadas foram identificadas por comparação, conforme descrição de Lorenzi (2008), e quantificadas de acordo com a família, gênero e espécie. Em seguida, as amostras de cada espécie foram acondicionadas em sacos de papel e encaminhadas à estufa de circulação forçada de ar a $65^{\circ} \mathrm{C}$ por $72 \mathrm{~h}$. Depois disso, eles foram pesados em uma balança de precisão, a fim de determinar a massa seca.

Através da coleta, quantificação e classificação das plantas daninhas foram avaliados a matéria seca, a frequência, frequência relativa, densidade, densidade relativa, abundância, abundância relativa, dominância relativa, índice de valor de importância, índice de valor de cobertura e o índice de similaridade. Foram determinados o número de indivíduos por espécie em cada parcela e o número total por coleta. A partir da identificação e contagem das espécies, foi realizado o cálculo das seguintes variáveis fitossociológicas:

Frequência (FR) - que permite avaliar a distribuição das espécies na área, Densidade (DE) - que quantifica as plantas de cada espécie por unidade de área, Abundância (AB) - que informa sobre a concentração das espécies na área, Frequência relativa (FRR),Densidade relativa (DER) - que informa em porcentagem, a participação de cada espécie em relação ao número total de indivíduos de todas as espécies, Abundância relativa (ABR) - que determina a relação de cada espécie com outras encontradas na área, Dominância relativa (DOR) - indica a dominância de cada espécie em relação à produção de biomassa, Índice de valor de importância (IVI) - que indica quais espécies são mais importantes dentro da área estudada (BRIGHENTI et al., 2003), Índice de valor de cobertura (IVC) - expressa a cobertura das espécies em relação à sua produção de biomassa e número de indivíduos por área (MULLER-DOMBOIS e ELLENBERG, 1974). Índice de similaridade (IS); expressa a similaridade de espécies em relação à área. 
Os índices relativos foram utilizados para o cálculo dos Índices de Valor de Importância expressos em forma de constante, e o índice de similaridade (IS) em porcentagem.

Para calcular tais variáveis, foram utilizadas as seguintes fórmulas:

$\mathrm{FR}=\mathrm{n}^{\circ}$ de quadrados que contém a espécie $/ \mathrm{n}^{\circ}$ total de quadrados obtidos.

FRR $=$ F da espécie $* 100 /$ Frequência total das espécies

$\mathrm{DE}=\mathrm{n}^{\circ}$ total de indivíduos por espécie / Área total ocupada pelos quadrados.

DER $=\mathrm{D}$ da espécie $* 100 /$ Densidade total das espécies

$\mathrm{AB}=\mathrm{n}^{\circ}$ total de indivíduos por espécie $/ \mathrm{n}^{\circ}$ total de quadrados que contém a espécie.

$\mathrm{ABR}=\mathrm{AB}$ da espécie $* 100 /$ Abundância total das espécies

DOR $=$ biomassa da espécie $/ \Sigma$ da biomassa total de todas as espécies *100.

$\mathrm{IVI}=\mathrm{FR}+\mathrm{DR}+\mathrm{AR}$

$\mathrm{IVC}=\mathrm{DOR}+\mathrm{DER}$

IS $=[(2 * a) /(b+c)] * 100$

em que: a é o número de espécies comuns aos dois estádios; b e c o número total de espécies nos dois estádios comparados.

\section{RESULTADOS}

Foi possível quantificar mais de 1.300 espécimes de plantas daninhas durante todo o ciclo da cultura, distribuídos em sete famílias e dez espécies, sendo $70 \%$ dicotiledôneas e 30\% monocotiledôneas (Tabelas 1). A família Fabaceae se destacou entre as dicotiledôneas, com

duas espécies ocorrentes, enquanto as demais famílias apresentaram apenas uma espécie cada. Dentre as monocotiledôneas a família Poaceae destacou-se, com três espécies (Tabela 1).

A massa seca das espécies de plantas daninhas foi crescente ao longo de todo ciclo, tendo o valor máximo de matéria seca obtida aos 63 dias após emergência da cultura (DAE), onde foram obtidos $1127 \mathrm{~g} \mathrm{~m}^{-2}$ (Tabela 2).

A espécie Portulaca oleracea foi a espécie que, durante quase todo o período de realização do levantamento, apresentou maior número de indivíduos por espécie, somando um valor total de 587 indivíduos, e assim obtendo também grande produção de matéria seca em relação as demais, e consequentemente maior densidade relativa (DER) e abundancia relativa (ABR) características que atribuem um grande valor de importância na área (Figura 1).

Aos 7 e 21 DAE, foram quantificados respectivamente 301 e 193 espécimes de plantas daninhas, sendo a maior densidade durante todo o levantamento ocorrida aos $7 \mathrm{DAE}$, com mais de 300 indivíduos por $\mathrm{m}^{-2}$ (Tabela 2). Nessas mesmas épocas de avaliação as espécies Portulaca oleracea, Sorghum bicolor apresentaram os maiores números de indivíduos e valor de massa de matéria seca, e consequentemente as maiores DER, FRR, ABR e IVI (Figura 1). Além de se destacar nessa época de avaliação, a espécie Sorghum bicolor também compôs os maiores valores de produção de massa de matéria seca em todo o período de realização do levantamento fitossociológico.

Além da espécie Portulaca Oleracea houveram algumas espécies que mesmo não se sobressaindo sobre a mesma, também apresentaram valores altos para matéria seca e para quantidade de indivíduos por espécie, como as espécies Sorghum bicolor, Cenchrus echinatus, Neonotonia wightii, Senna obustifolia.

Em relação a dominância relativa (DOR) as espécies que se destacaram, durante o cultivo do feijão-caupi em relação à produção de biomassa na maioria dos levantamentos foram: Portulaca oleracea (56,21 aos 21 DAE), Sorghum bicolor (73,11 aos 63 DAE) e Senna obtusifolia (19,24 aos 14 DAE) (Tabela 3).

Observando os dados relacionados ao Índice de Valor de Cobertura (IVC), pode-se dizer que as espécies que apresentaram os maiores valores foram Portulaca oleracea (108,55 aos 21 DAE), Sorghum bicolor (89,24 aos 63 DAE) e Senna obustifolia (50,78 aos $49 \mathrm{DAE})$, podendo assim serem ditas como as espécies que possuíram a maior cobertura da área durante os períodos citados (Tabela 3). As espécies Portulaca oleracea e Sorghum bicolor se destacaram em quase todos os levantamentos, apresentando valores muito superiores as demais espécies.

Para a variável Índice de Similaridade (IS), os resultados obtidos foram os seguintes: $100 \%$ aos 7 e 14 DAE e aos 49 e 56 DAE respectivamente, o que indica que houve homogeneidade durante alguns períodos da condução da cultura do feijão-caupi em relação a solo, clima e banco de sementes. Já o menor IS foi de 71,43\% e ocorreu aos (21 e 49), (21 e 56), (28 e 49) e (28 e 56) DAE o que indica que houveram mudanças na comunidade infestante durante estes períodos da condução da cultura, e assim sobressaindo as espécies que melhor se adaptaram as condições de cultivo (Tabela 4). Valores obtidos acima de $25 \%$ indicam que há similaridade entre os fatores analisados, sendo assim, é possível afirmar que mesmo nos períodos em que houver os menores valores de IS, ainda assim houve similaridade.

Tabela 1. Plantas daninhas encontradas em cultivo de feijão-caupi, cultivar BRS ITAIM, safra inverno, Janaúba-Mg, 2017. Table 1. Weeds found in cowpea cultivation, cultivar BRS ITAIM, winter crop, Janaúba-MG, 2017.

\begin{tabular}{|c|c|c|c|c|c|}
\hline \multirow{2}{*}{ Família } & \multirow{2}{*}{ Gênero } & \multicolumn{4}{|c|}{ Espécie } \\
\hline & & Nome científico & Nome comum & Classe & Sistema fotossintético \\
\hline Amaranthaceae & Amaranthus & Amaranthus viridis & Caruru & Magnoliopsida & $\mathrm{C} 4$ \\
\hline Asteraceae & Acanthospermum & Acanthospermum bispidum & Carrapicho-de-carneiro & Magnoliopsida & C3 \\
\hline Convolvulaceae & Ipomoea & Ipomoea grandifolia & Corda-de-viola & Magnoliopsida & C3 \\
\hline Fabaceae & Senna & Senna obtusifolia & Mata-pasto & Magnoliopsida & C3 \\
\hline Fabaceae & Neonotonia & Neonotonia wightii & Soja-Perene & Magnoliopsida & C3 \\
\hline Malvaceae & Malvastrum & Malvastrum coromandelianum & Guanxuma & Magnoliopsida & $\mathrm{C} 3$ \\
\hline Poaceae & Cenchrus & Cenchrus echinatus & Capim-carrapicho & Liliopsida & $\mathrm{C} 4$ \\
\hline Poaceae & Dactyloctenium & Dactyloctenium aegyptium & Capim-mão-de sapo & Liliopsida & $\mathrm{C} 4$ \\
\hline Poaceae & Sorghum & Sorghum bicolor & Sorgo & Liliopsida & $\mathrm{C} 4$ \\
\hline Portulacaceae & Portulaca & Portulaca oleracea & Beldroega & Magnoliopsida & $\mathrm{C} 4$ \\
\hline
\end{tabular}


Tabela 2. Massa seca (MS) em gramas e Número de indivíduos por espécie (NIE) de plantas daninhas no cultivo de feijão-caupi cultivar BRS ITAIM, safra de inverno, Janaúba-MG, 2017.

Table 2. Dry mass (DM) in grams and Number of individuals per species (NIS) of weeds in the cultivation of cowpea cultivar BRS ITAIM, winter crop, Janaúba-MG, 2017.

\begin{tabular}{|c|c|c|c|c|c|c|c|c|}
\hline \multicolumn{9}{|c|}{ ÉPOCAS DE COLETA } \\
\hline 7 dias após Emergência & & & 14 dias após Emergência & & & 21 dias após Emergência & & \\
\hline Planta daninha & MS & NIE & Planta daninha & MS & NIE & Planta daninha & MS & NIE \\
\hline Acanthospermum hispidum & 0 & 1 & Acanthospermum hispidum & 8,9 & 8 & Acanthospermum hispidum & 2,09 & 13 \\
\hline Amaranthus viridis & 1,4 & 29 & Amaranthus viridis & 35 & 13 & Amaranthus viridis & 2,64 & 14 \\
\hline Ipomoea grandifolia & 2,9 & 11 & Ipomoea grandifolia & 22 & 7 & Cenchrus echinatus & 33,8 & 22 \\
\hline Portulaca oleracea & 17 & 165 & Portulaca oleracea & 39 & 65 & Ipomoea grandifolia & 1,14 & 1 \\
\hline Senna obustifolia & 2,2 & 26 & Senna obustifolia & 36 & 20 & Portulaca oleracea & 99,65 & 101 \\
\hline Sida sp. & 1,4 & 7 & Sida sp. & 17 & 4 & Senna obustifolia & 8,03 & 14 \\
\hline Sorghum bicolor & 11 & 62 & Sorghum bicolor & 28 & 7 & Sida sp. & 1,99 & 7 \\
\hline- & - & - & - & - & - & Sorghum bicolor & 27,93 & 21 \\
\hline Total da coleta & 36 & 301 & Total da coleta & 185 & 124 & Total da coleta & 177,3 & 193 \\
\hline 28 dias após emergência & & & 35 dias após emergência & & & 42 dias após emergência & & \\
\hline Planta daninha & MS & NIE & Planta daninha & MS & NIE & Planta daninha & MS & NIE \\
\hline Amaranthus viridis & 2,6 & 14 & Acanthospermum hispidum & 3,9 & 1 & Acanthospermum hispidum & 11,11 & 5 \\
\hline Cenchrus echinatus & 34 & 22 & Amaranthus viridis & 0,6 & 1 & Amaranthus viridis & 3,81 & 7 \\
\hline Ipomoea grandifolia & 5,2 & 4 & Ipomoea grandifolia & 11 & 2 & Cenchrus echinatus & 10,79 & 3 \\
\hline Neonotonia wightii & 28 & 11 & Neonotonia wightii & 36 & 22 & Ipomoea grandifolia & 25,74 & 6 \\
\hline Portulaca oleracea & 86 & 43 & Portulaca oleracea & 217 & 44 & Neonotonia wightii & 55,93 & 18 \\
\hline Senna obustifolia & 13 & 7 & Senna obustifolia & 12 & 3 & Portulaca oleracea & 300,9 & 72 \\
\hline Sida sp. & 2 & 7 & Sorghum bicolor & 164 & 8 & Senna obustifolia & 44,75 & 6 \\
\hline Sorghum bicolor & 195 & 28 & - & - & - & Sida sp. & 6,18 & 6 \\
\hline- & - & - & - & - & - & Sorghum bicolor & 478,1 & 19 \\
\hline Total da coleta & 365 & 136 & Total da coleta & 443 & 81 & Total da coleta & 937,3 & 142 \\
\hline 49 dias após emergência & & & 56 dias após emergência & & & 63 dias após emergência & & \\
\hline Planta daninha & MS & NIE & Planta daninha & MS & NIE & Planta daninha & MS & NIE \\
\hline Acanthospermum hispidum & 3,7 & 6 & Acanthospermum hispidum & 17 & 20 & Acanthospermum hispidum & 2,68 & 3 \\
\hline Ipomoea grandifolia & 35 & 8 & Ipomoea grandifolia & 36 & 10 & Amaranthus viridis & 2,59 & 3 \\
\hline Neonotonia wightii & 60 & 16 & Neonotonia wightii & 61 & 31 & Dactyloctenium aegyptium & 25,74 & 22 \\
\hline Portulaca oleracea & 80 & 27 & Portulaca oleracea & 97 & 62 & Ipomoea grandifolia & 75,28 & 17 \\
\hline Senna obustifolia & 185 & 31 & Senna obustifolia & 93 & 16 & Neonotonia wightii & 45,11 & 11 \\
\hline Sorghum bicolor & 635 & 8 & Sorghum bicolor & 650 & 8 & Portulaca oleracea & 34,66 & 8 \\
\hline- & - & - & - & - & - & Senna obustifolia & 116,9 & 14 \\
\hline- & - & - & - & - & - & Sorghum bicolor & 823,6 & 15 \\
\hline Total da coleta & 999 & 96 & Total da coleta & 954 & 147 & Total da coleta & 1127 & 93 \\
\hline
\end{tabular}

“_“ = Não existência de plantas daninhas na determinada coleta.

Tabela 3. Dominância Relativa (DOR) e Índice de valor de cobertura (IVC) de plantas daninhas no cultivo de feijão-caupi, cultivar BRS ITAIM, safra de inverno, Janaúba-MG, 2019.

Table 3. Relative Dominance (RD) and Cover Value Index (CVI) of weeds in the cultivation of cowpea, cultivar BRS ITAIM, winter crop, Janaúba-MG, 2019.

\begin{tabular}{|c|c|c|c|c|c|c|c|c|}
\hline \multicolumn{9}{|c|}{ ÉPOCAS DE COLETA } \\
\hline 7 dias após emergência & & & 14 dias após emergência & & & 21 dias após emergência & & \\
\hline Planta daninha & DOR & IVC & Planta daninha & DOR & IVC & Planta daninha & DOR & IVC \\
\hline Acanthospermum hispidum & 0,11 & 0,44 & Acanthospermum hispidum & 4,81 & 11,26 & Acanthospermum hispidum & 1,18 & 7,91 \\
\hline Amaranthus viridis & 3,99 & 13,62 & Amaranthus viridis & 18,86 & 29,35 & Amaranthus viridis & 1,49 & 8,74 \\
\hline Ipomoea grandifolia & 8,14 & 11,79 & Ipomoea grandifolia & 11,95 & 17,59 & Cenchrus echinatus & 19,07 & 30,47 \\
\hline Portulaca oleracea & 47,62 & 102,43 & Portulaca oleracea & 20,86 & 73,28 & Ipomoea grandifolia & 0,64 & 1,16 \\
\hline Senna obustifolia & 6,19 & 14,83 & Senna obustifolia & 19,24 & 35,37 & Portulaca oleracea & 56,21 & 108,55 \\
\hline Sida sp. & 3,82 & 6,14 & Sida sp. & 9,03 & 12,25 & Senna obustifolia & 4,53 & 11,78 \\
\hline Sorghum bicolor & 30,14 & 50,73 & Sorghum bicolor & 15,24 & 20,89 & Sida sp. & 1,12 & 4,75 \\
\hline- & - & - & - & - & - & Sorghum bicolor & 15,76 & 26,64 \\
\hline 28 dias após emergência & & & 35 dias após emergência & & & 42 dias após emergência & & \\
\hline Planta daninha & DOR & IVC & Planta daninha & DOR & IVC & Planta daninha & DOR & IVC \\
\hline Amaranthus viridis & 0,72 & 11,02 & Acanthospermum hispidum & 0,88 & 2,11 & Acanthospermum bispidum & 1,19 & 4,71 \\
\hline Cenchrus echinatus & 9,26 & 25,43 & Amaranthus viridis & 0,13 & 1,37 & Amaranthus viridis & 0,41 & 5,34 \\
\hline Ipomoea grandifolia & 1,43 & 4,37 & Ipomoea grandifolia & 2,44 & 4,91 & Cenchrus echinatus & 1,15 & 3,26 \\
\hline Neonotonia wightii & 7,68 & 15,76 & Neonotonia wightii & 8,13 & 35,29 & Ipomoea grandifolia & 2,75 & 6,97 \\
\hline Portulaca oleracea & 23,55 & 55,17 & Portulaca oleracea & 48,89 & 103,22 & Neonotonia wightii & 5,97 & 18,64 \\
\hline Senna obustifolia & 3,48 & 8,63 & Senna obustifolia & 2,60 & 6,30 & Portulaca oleracea & 32,10 & 82,81 \\
\hline Sida sp. & 0,54 & 5,69 & Sorghum bicolor & 36,93 & 46,81 & Senna obustifolia & 4,77 & 9,00 \\
\hline Sorghum bicolor & 53,34 & 73,93 & - & - & - & Sida sp. & 0,66 & 4,88 \\
\hline- & - & - & - & - & - & Sorghum bicolor & 51,01 & 64,39 \\
\hline 49 dias após emergência & & & 56 dias após emergência & & & 63 dias após emergência & & \\
\hline Planta daninha & DOR & IVC & Planta daninha & DOR & IVC & Planta daninha & DOR & IVC \\
\hline Acanthospermum hispidum & 0,37 & 6,62 & Acanthospermum hispidum & 1,78 & 15,39 & Acanthospermum hispidum & 0,24 & 3,46 \\
\hline Ipomoea grandifolia & 3,53 & 11,87 & Ipomoea grandifolia & 3,79 & 10,59 & Amaranthus viridis & 0,23 & 3,46 \\
\hline Neonotonia wightii & 6,01 & 22,68 & Neonotonia wightii & 6,37 & 27,46 & Dactyloctenium aegyptium & 2,28 & 25,94 \\
\hline Portulaca oleracea & 8,02 & 36,15 & Portulaca oleracea & 10,16 & 52,34 & Ipomoea grandifolia & 6,68 & 24,96 \\
\hline Senna obustifolia & 18,48 & 50,78 & Senna obustifolia & 9,76 & 20,65 & Neonotonia wightii & 4,00 & 15,83 \\
\hline Sorgo (Sorghum bicolor) & 63,57 & 71,91 & Sorgo (Sorghum bicolor) & 68,13 & 73,57 & Portulaca oleracea & 3,08 & 11,68 \\
\hline $4+$ & - & - & 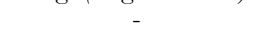 & - & - & Senna obustifolia & 10,37 & 25,43 \\
\hline- & - & - & - & - & - & Sorghum bicolor & 73,11 & 89,24 \\
\hline
\end{tabular}



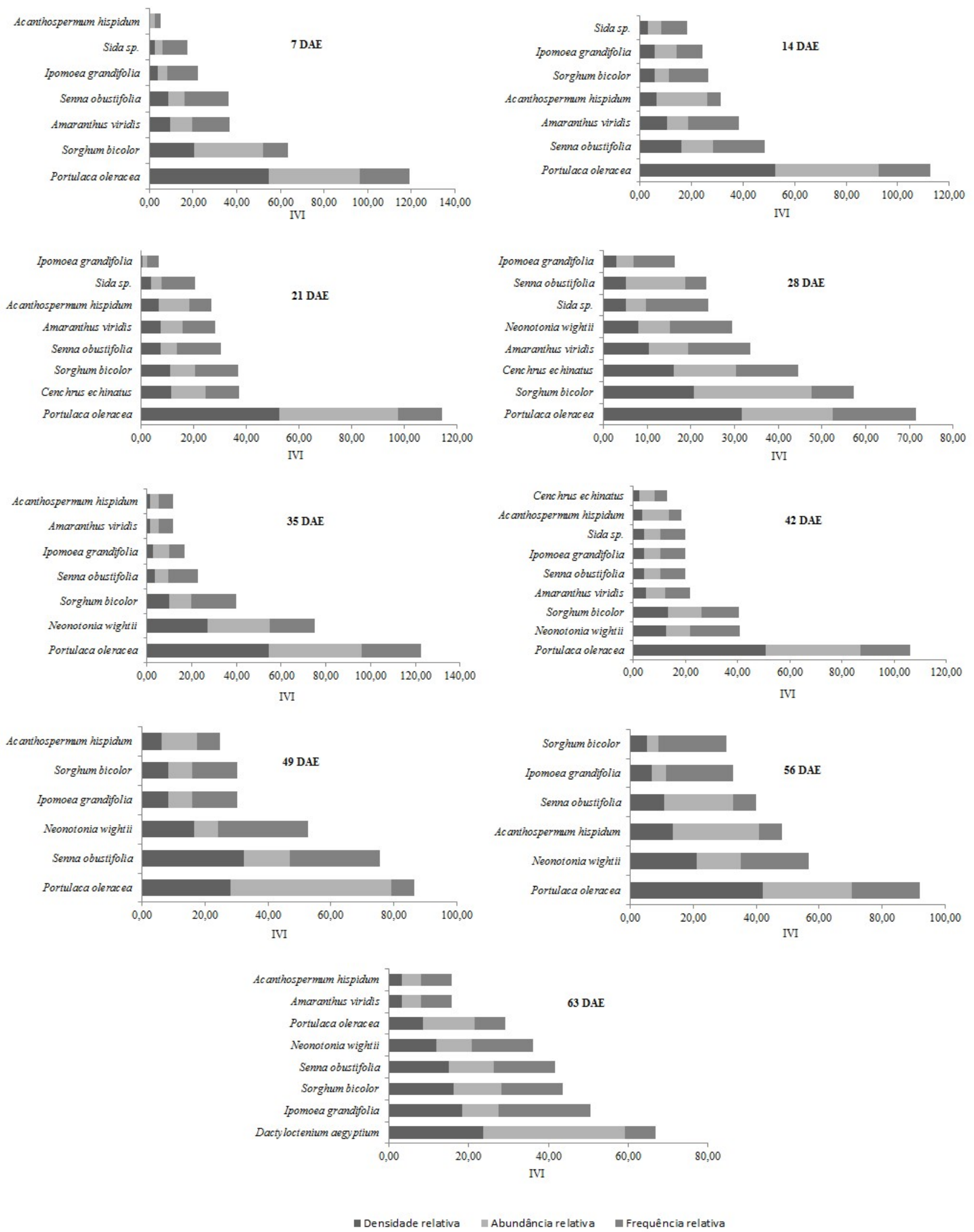

Figura 1. Índice de valor de importância (IVI) das principais espécies de plantas daninhas coletadas dias após emergência (DAE), na área de feijão-caupi, cultivar BRS ITAIM, safra de inverno, Janaúba-MG, 2017.

Figure 1. Importance value index (IVI) of the main weed species collected days after emergence (DAE), in the cowpea area, cultivar BRS ITAIM, winter crop, Janaúba-MG, 2017. 
Tabela 4. Índice de Similaridade (IS) das coletas de plantas daninhas, no cultivo de feijão-caupi, cultivar BRS ITAIM safra de inverno, Janaúba-MG, 2019.

Table 4. Similarity Index (SI) of weed collections, in cowpea cultivation, cultivar BRS ITAIM, winter crop, Janaúba-MG, 2019.

\begin{tabular}{|c|c|c|c|c|c|c|c|c|c|}
\hline \multicolumn{10}{|c|}{ IS $(\%)$} \\
\hline Critério de Comparação & $7 \mathrm{DAE}$ & $14 \mathrm{DAE}$ & $21 \mathrm{DAE}$ & $28 \mathrm{DAE}$ & $35 \mathrm{DAE}$ & $42 \mathrm{DAE}$ & $49 \mathrm{DAE}$ & $56 \mathrm{DAE}$ & $63 \mathrm{DAE}$ \\
\hline $7 \mathrm{DAE}$ & - & 100,0 & 80,0 & 80,0 & 85,71 & 87,5 & 76,92 & 76,92 & 80,0 \\
\hline $14 \mathrm{DAE}$ & - & - & 80,0 & 80,0 & 85,71 & 87,5 & 76,92 & 76,92 & 80,0 \\
\hline $21 \mathrm{DAE}$ & - & - & - & 87,5 & 80,0 & 94,12 & 71,43 & 71,43 & 75,0 \\
\hline $28 \mathrm{DAE}$ & - & - & - & - & 80,0 & 94,12 & 71,43 & 71,43 & 75,0 \\
\hline $35 \mathrm{DAE}$ & - & - & - & - & - & 87,5 & 92,31 & 92,31 & 93,33 \\
\hline $42 \mathrm{DAE}$ & - & - & - & - & - & - & 80,0 & 80,0 & 82,35 \\
\hline $49 \mathrm{DAE}$ & - & - & - & - & - & - & - & 100,0 & 85,71 \\
\hline $56 \mathrm{DAE}$ & - & - & - & - & - & - & - & - & 85,71 \\
\hline $63 \mathrm{DAE}$ & - & - & - & - & - & - & - & - & - \\
\hline
\end{tabular}

“_“ = Não existência de plantas daninhas na determinada coleta.

\section{DISCUSSÃO}

Corrêa et al. (2015), em trabalhos realizados com interferência de plantas daninhas na cultura do feijão-caupi, obtiveram valores de $82 \%$, para plantas daninhas do tipo dicotiledônea. Possivelmente a maior ocorrência de plantas daninhas dicotiledôneas é causada devido ao fato destas serem pertencentes a mesma classe do feijão, tornando assim mais difícil o seu controle por apresentarem semelhanças quanto a morfologia e fisiologia.

Devido ao controle de plantas monocotiledôneas como as gramíneas no cultivo do feijão-caupi ser mais fácil por ser possível diferencia-las com maior facilidade da cultura de interesse durante a capina e também quando o controle é realizado de forma química, o banco de sementes de plantas daninhas do tipo dicotiledôneas presentes no solo será maior, o que também explica a maior ocorrência destas em áreas de cultivo do feijão-caupi.

Estudos de levantamentos realizados por Marques et al. (2010) e Batista et al. (2016), na cultura do feijão-caupi e feijão-comum, respectivamente, mostraram que, as famílias Asteraceae, Malvaceae e Poaceae, foram as que apresentaram o maior número de espécies.

No geral, a maior parte das plantas daninhas que compuseram comunidade infestante durante todo o levantamento foi composta por plantas de metabolismo fotossintético do tipo $\mathrm{C} 4$, isso se deve ao fato de que pelas plantas do tipo $\mathrm{C} 4$ serem mais adaptadas a climas quentes e secos e regiões áridas em relação as plantas do tipo C3, acabam por se sobressaírem na competição por nutrientes, água e luz solar, o que resulta em um número maior de plantas deste tipo nas áreas de plantio.

Foi possível encontrar plantas da família Portulacaceae em todos os períodos avaliados, tais como Portulaca oleracea, que de acordo com Lorenzi (2008), é uma planta daninha comum em todo o território nacional que se propaga por meio de sementes e é capaz de germinar durante todo o ano, tendo ciclo de vida curto, em tono de 60 dias. É considerada como uma planta prolífica, pois uma única planta pode produzir mais de 10.000 sementes que podem permanecer dormentes no solo por até mais de 19 anos.

A morfologia da planta é um dos fatores principais relacionados à capacidade do feijoeiro em competir om as plantas daninhas. Segundo Santos; Gavilanes (2006) Genótipos que apresentam hábito de crescimento ereto e são pouco ramificados, tendem a ser menos competitivos quando comparados com genótipos de porte prostrado e semiprostrado, sendo estes cultivados na maioria das vezes, promovendo uma maior cobertura do solo. Batista et al. (2017), em trabalho onde avaliou a fitossociologia de plantas daninhas em cultivares de feijão-caupi com porte ereto e prostrado, na região do semiárido mineiro, relatou que ocorreu maior desenvolvimento de daninhas com sistema fotossintético do tipo $\mathrm{C} 4$, nas cultivares de feijão-capi de porte ereto.

Assim pode-se dizer que as espécies Portulaca oleracea, Amaranthus viridis, Sorgbum bicolor puderam se beneficiar da maior incidência de luz que ocorreu nas entrelinhas de plantio devido ao porte ereto das plantas de feijão-caupi podendo atingir IVI acima de $50 \mathrm{em}$ praticamente todo o período de realização do levantamento fitossociológico. Segundo Lacerda (2019), cultivares de feijão-caupi de porte mais ereto que causam um menor sombreamento do solo costumam sofrer mais com interferência causada pelas das plantas daninhas, o que resulta em atrasos no crescimento e perdas de produtividade, que no feijão chegam a atingir cerca de 67\%. Batista et al. (2017) apresentou resultados semelhantes, em levantamento fitossociológico de plantas daninhas com cultivares de feijão-comum de tipos de crescimento diferentes, no Norte de Minas Gerais. De acordo com Teixeira et al. (2009) e Manabe et al. (2015), a competição entre o feijoeiro e as plantas daninhas reduz o crescimento da cultura, porém as cultivares de feijão que possuem porte mais prostrado, tendem a competir mais e diminui o crescimento das comunidades infestantes de plantas espontâneas durante o seu cultivo.

O índice de valor de cobertura (IVC) é uma característica que leva em consideração a produção de biomassa das espécies em função do número de indivíduos por área, sendo assim é possível dizer que inicialmente a espécie Portulaca oleracea obteve destaque pela sua grande distribuição na área, e consequentemente produzir altos valores de biomassa, e ao final do ciclo da cultura devido ao desenvolvimento e fechamento da área pelas plantas de feijão-cupi, o número de indivíduos dessa espécie reduziu drasticamente devido a competição por água luz e nutrientes, e assim, a espécie Sorghum bicolor obteve destaque por ser uma planta que mesmo apresentando um menor número de indivíduos na área, produz altos valores de biomassa.

De acordo com Kuva et al. (2007) o índice de similaridade não considera informações de biomassa, densidade e padrão de distribuição, considerando apenas a ausência ou presença das espécies ou conjunto de plantas, e ressaltam, também, que este índice é normalmente calculado por meio das espécies individuais ocorrentes. Os índices de similaridade apresentam relação entre áreas sob as mesmas condições ambientais, no qual às diferenças podem ser atribuídas pela ação antrópica e pelas formas com que o manejo é realizado nessas áreas (CALDEIRA et al., 2013). Essas mudanças 
podem ter influência sobre os processos de germinação e desenvolvimento das plantas daninhas e, assim podem influenciar nas estratégias adotadas para o manejo das plantas daninhas que possuem um maior grau de importância.

De acordo com Felfili; Venturoli (2000), o Índice de Similaridade é considerado como alto quando é superior a $50 \%$, sendo assim, é possível concluir que houve alta similaridade das espécies encontradas neste levantamento fitossociológico.

Por meio do índice de similaridade é possível descobrir se as espécies de plantas daninhas existentes na área são semelhantes durante todos ou em determinados períodos da condução da cultura, e com essas informações é possível definir os melhores métodos de manejo para a cultura, podendo assim saber se será possível utilizar das mesmas técnicas de manejo durante todo o ciclo da cultura para quando a similaridade florística for alta, ou se será necessário adotar diferentes técnicas de manejo ao longo do desenvolvimento da cultura para quando a similaridade florística de espécies de plantas daninhas for baixa.

\section{CONCLUSÕES}

As espécies Portulaca oleracea, Amaranthus viridis (dicotiledôneas) e Sorghum bicolor (monocotiledônea) representam as espécies que apresentaram o maior IVI, considerando todo o ciclo da cultura. É alta a similaridade florística das espécies de plantas daninhas que ocorreram durante toda a condução do feijão-caupi. Para a característica Índice de valor de Cobertura (IVC), as espécies que obtiveram destaque foram Portulaca oleracea, Sorghum bicolor e Senna obustifolia.

\section{REFERÊNCIAS}

ANDRADE, F. N. Avaliação e seleção de linhagens de tegumento e cotilédones verdes para o mercado de feijão-caupi verde. 2010. 110 f. Dissertação (Mestrado em Agronomia) - Universidade Federal do Piauí, Teresina, 2010.

BATISTA, P. S. C.; OLIVEIRA, V. S.; CAXITO, A. M.; CARVAlHO, A. J.; ASPIAZÚ, I. Phytosociological survey of weeds in cultivars of common beans with different types of growth in the north of Minas Gerais. Planta Daninha, v. 34, p. 497-507, 2016. DOI: http:/ /dx.doi.org/10.1590/s0100-83582016340300010

BATISTA, P. S. C.; OLIVEIRA, V. S.; SOUZA, V. B.; CARVALHO, A. J.; ASPIAZÚ, I. Phytosociological survey of weeds in erect prostrate cowpea cultivars. 2017. Planta Daninha, v. 35, e017160273, 2017. DOI: https://doi.org/10.1590/S0100-83582017350100031

BRAUN-BLANQUET, J. Fitossociologia: bases para el estudio de las comunidades vegetales. Madrid: $H$. Blume, 1979. 820p.

BRIGHENTI, A. M.; CASTRO, C. de; GAZZIERO, D. L. P.; ADEGAS, F. S. Cadastramento fitossociológico de plantas daninhas na cultura de girassol. Pesquisa Agropecuária Brasileira, v. 38, n. 5, p. 651-657, 2003. DOI: https://doi.org/10.1590/S0100204X2003000500014

CALDEIRA, D. S. A.; MOREIRA, M. D. S.; CASADEI, R. A. Levantamento fitossociológico em pastagens de Brachiaria brizantha cv. Marandu com diferentes idades em Mato Grosso. Tecnologia \& Ciência Agropecuária, João Pessoa, v. 7, n. 1, p. 35-40, 2013.

CONAB_Companhia Nacional de Abastecimento. Acompanhamento da safra brasileira de grãos - v. 6 SAFRA 2018/19 - N. 7 - abril 2019. Disponível em: < https://www.conab.gov.br/info-

agro/safras/graos/boletim-da-safra-deraos/item/download/25555_b333e4934dda849cfa515b 5a306ebfca > Acesso em: 20 abr. 2019

CORRÊA, M. J. P.; ALVES, G. L.; ROCHA, L. R. F.; SILVA, R. M. Períodos de interferência de plantas daninhas na cultura do feijão caupi. Revista de Ciências Agroambientais, Alta Floresta, v. 13, n. 2, p. 50-56, 2015. DOI: https://doi.org/10.5327/rcaa.v13i2.1183

EMBRAPA_Empresa Brasileira de Pesquisa Agropecuária. FEIJÃO-CAUPI: melhoramento genético para o avanço da cultura. Teresina: Embrapa Meio-Norte, 2016. 6p. (Folders). Disponível em: https://ainfo.cnptia.embrapa.br/digital/bitstream/item /144703/1/FeijaoCaupiAvancoCultura2016.pdf

FELFILI, J. M.; VENTUROLI, F. Tópicos em análise de vegetação. Comunicações Técnicas Florestais, v. 2, n. 2, p.1-25, 2000. Disponível em: https:// files.cercomp.ufg.br/weby/up/417/o/T\%C3\% 93PICOS_EM_AN $\%$ C3\%81LISE_DE_VEGETA $\%$ C3 $\% 87 \%$ C3\%83O.pdf? 1636382600

FREIRE FILHO, F. R. (Org.). Feijão-caupi no Brasil: produção, melhoramento genético, avanços e desafios. Teresina: Embrapa Meio-Norte, 2011. 84p. Disponível em: https://ainfo.cnptia.embrapa.br/digital/bitstream/item /84470/1/feijao-caupi.pdf

KUVA, M. A.; PITELLI, R. A.; SALGADO, T. P.; ALVES, P. L. C. A. Fitossociologia de comunidades de plantas daninhas em agroecossistema cana-crua. Planta Daninha, v. 25, n. 3, p. 501-511, 2007. DOI: https://doi.org/10.1590/S0100-83582007000300009

LIMA, R. S.; SÃO JOSÉ, A. R.; SOARES, M. R. S.; MOREIRA, E. S.; ARAUJO NETO, A. C.; CARDOSO, A. D.; MORAIS, O. M. Levantamento fitossociológico de plantas daninhas na cultura do feijão-caupi no município de Vitória da Conquista-BA. Magistra, v. 28, n. 3/4, p. 390-402, 2016.

LORENZI H. Plantas daninhas do Brasil: terrestres, aquáticas, parasitas e tóxicas. 4 ed. Nova Odessa: Instituto Plantarum, 2008. 672 p.

MANABE, P. M. S.; MATOS, C.; FERREIRA, E. A.; SILVA, A. F.; SILVA, A. A.; SEDIYAMA, T.; MANABE, A.; RIBEIRO, P. R.; SILVA, C. T. da. Efeito da competição de plantas daninhas na cultura do Feijoeiro. Bioscience Journal, Uberlândia, v. 31, n. 2, p. 333-343, 2015. DOI: 10.14393/bj-v31n2a2015-22271

MARQUES, L. J. P.; SILVA, M. R. M.; ARAUJO, M. S.; LOPES, G. S.; CORRÊA, M. J. P.; FREITAS, A. C. R.; MUNIZ, F. H. Composição florística de plantas daninhas na cultura do feijão-caupi no sistema de capoeira triturada. Planta Daninha, v. 28, p. 953-61, 2010. DOI: http://dx.doi.org/10.1590/S0100-83582010000500003

MUELLER-DOMBOIS D, ELLENBERG H. Aims and methods of vegetation ecology. New York: John Wiley \& Sons, 1974. 574P.

LACERDA, M. L. Interferência de plantas daninhas na cultura do feijão-caupi no semiárido mineiro. 2017. 
77p. Dissertação (Mestrado em Produção Vegetal no Semiárido) - Unimontes, Montes Claros, 2017.

OLIVEIRA, O. M. S.; SILVA, J. F.; GONÇALVES, J. R. P. Período de convivência das plantas daninhas com cultivares de feijão-caupi em Várzea do Amazonas. Planta Daninha, v. 28, n. 3., p. 523-530, 2010. DOI: https://doi.org/10.1590/S0100-83582010000300009

SANTOS, J. B.; GAVILANES, M. L. Botânica. In: VIEIRA, C.; PAULA JÚNIOR, T. J.; BORÉM, A. (Eds.). Feijão. 2 ed. Viçosa: Editora UFV, 2006. p. 41-66.

TEIXEIRA, I. R.; SILVA, R. P.; SILVA, A. G.; FREITAS, R. S. Competição entre feijoeiros e plantas daninhas em função do tipo de crescimento dos cultivares. Planta Daninha, MG, v. 27, n. 2, p. 235-240, 2009. DOI: https://doi.org/10.1590/S0100-83582009000200004

VASCONCELOS, M. C. C.; SILVA, A. F. A.; LIMA, R. S. Interferência de plantas daninhas sobre plantas cultivadas. Agropecuária Científica no Semi-Árido, v. 8, n.1, p. 1-6, 2012. 